\title{
Lymphoepithelial cyst of the pancreas mimicking malignant cystic tumor: report of a case
}

\author{
Dong Hee Ryu ${ }^{1}$, Ro Hyun Sung ${ }^{2}$, Min Ho Kang ${ }^{3}$, and Jae Woon Choi ${ }^{1}$ \\ Departments of ${ }^{1}$ Surgery, ${ }^{2}$ Pathology, and ${ }^{3}$ Radiology, Chungbuk National University, \\ College of Medicine and Medical Research Institute, Cheongju, Korea
}

\begin{abstract}
Lymphoepithelial cysts of the pancreas are a type of true cyst that can mimic pseudocysts and cystic neoplasms. They are very rare, non-malignant lesions that are unilocular or multilocular cystic lesions lined predominantly by mature squamous epithelium and surrounded by non-neoplastic lymphoid elements. We, herein, present a patient with a cystic pancreas tumor mimicking a malignant cystic neoplasm. The patient was admitted with upper abdominal discomfort. Computed tomography showed a $64 \times 39 \mathrm{~mm}$ cystic mass in the pancreas tail. She underwent distal pancreatectomy and splenectomy. In the fluid analysis of the pancreas cystic mass, the CEA and CA19-9 were $618 \mathrm{ng} / \mathrm{ml}$ and 3.9 $\mathrm{U} / \mathrm{ml}$, respectively. The resected pancreas specimen showed a $6.5 \mathrm{~cm}$-sized cyst the pancreas tail. The cyst was well circumscribed and multilocular. The final pathology report of the resected pancreas specimen noted that the cyst was multilocular, and the cyst lining was showing stratified squamous epithelium covering the lymphoid tissue (containing lymphoid follicles), which was consistent with a lymphoepithelial cyst. The patient recovered uneventfully from surgery and has been doing well for the past 3 months. A differential diagnosis of cystic pancreatic lesions is important. We suggest that lymphoepithelial cysts, although very rare, may be included in the differential diagnosis of cystic pancreatic tumors. (Korean J Hepatobiliary Pancreat Surg 2015;19:129-132)
\end{abstract}

Key Words: Lymphoepithelial cysts; Cystic neoplasms; Pancreas

\section{INTRODUCTION}

Cystic lesions of the pancreas are relatively rare and they are divided into true cysts, pseudocysts, and cystic neoplasms. ${ }^{1}$ In adults, $85 \%-90 \%$ of these lesions are pseudocysts, and they usually occur as a complication of pancreatitis. True cysts are most often neoplastic. A true cyst is distinguished by the presence of an epithelial lining, indicating its benign natural history and developmental origin.

Lymphoepithelial cysts are very rare, non-malignant lesions that were first described by Lüchtrath and Schriefers in $1985 .^{2}$ Lymphoepithelial cysts are true pancreatic cysts that are lined by squamous epithelium and surrounded by mature lymphoid tissue. The cyst arises typically in middle-aged men, and is usually either asymptomatic, or it causes nonspecific abdominal symptoms.
It has been thought to be difficult to differentiate lymphoepithelial cysts from other pancreatic lesions, such as serous cystic neoplasms, mucinous cystic neoplasms and intraductal papillary mucinous neoplasms, because the appearance of the lymphoepithelial cyst on imaging varies from patient to patient and sometimes is similar to other pancreatic lesions. ${ }^{3}$ The clinical and pathologic features of lymphoepithelial cysts are not yet fully characterized. We, herein, report a case of an lymphoepithelial cyst of the pancreas.

\section{CASE}

A 44-year-old woman presented with an alleged intra-abdominal mass on routine health screening. Her past medical history consisted of a Caesarean section, 10 years previously. When she visited our hospital, she had no ab-

Received: June 10, 2015; Revised: July 30, 2015; Accepted: August 15, 2015

Corresponding author: Jae Woon Choi

Department of Surgery, Chungbuk National University, College of Medicine and Medical Research Institute, 1 Chungdae-ro, Seowon-gu, Cheongju 28644, Korea

Tel: +82-43-269-6358, Fax: +82-43-266-6037, E-mail: jwchoi@chungbuk.ac.kr

Copyright (C) 2015 by The Korean Association of Hepato-Biliary-Pancreatic Surgery

This is an Open Access article distributed under the terms of the Creative Commons Attribution Non-Commercial License (http://creativecommons.org/ licenses/by-nc/4.0) which permits unrestricted non-commercial use, distribution, and reproduction in any medium, provided the original work is properly cited. Korean Journal of Hepato-Biliary-Pancreatic Surgery - pISSN: $1738-6349 \cdot$ eISSN: $2288-9213$ 


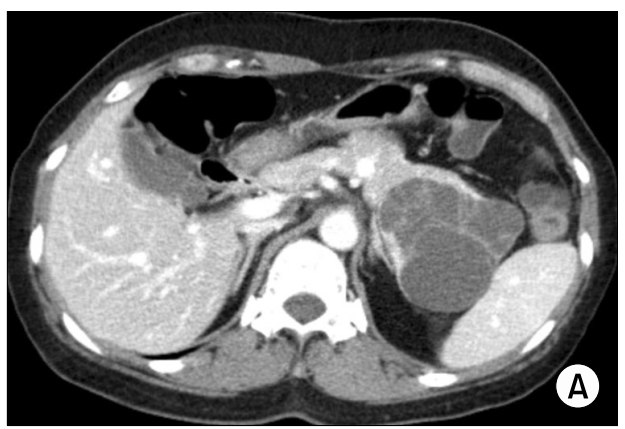

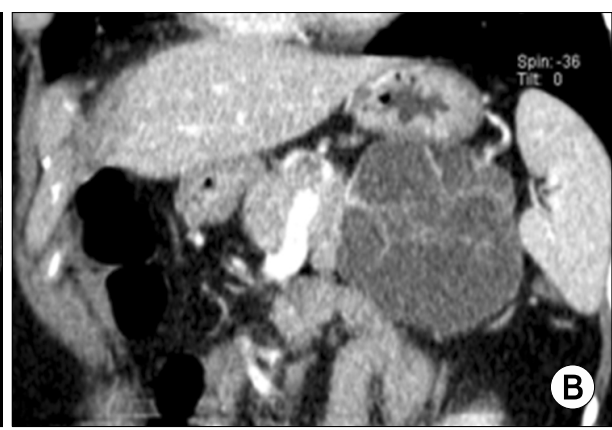

Fig. 1. Preoperative computed tomography images: Axial (A) and coronal (B) contrast-enhanced images show a large cystic mass with internal septa in the tail of the pancreas.

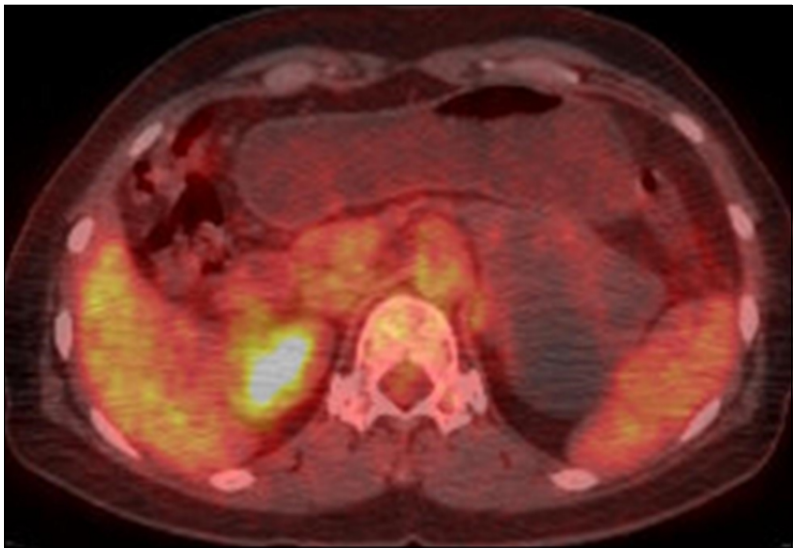

Fig. 2. The transaxial FDG PET-CT image shows no abnormal FDG tracer uptake at the pancreatic cystic mass.

normal physical findings, except for the palpable mass. On a blood tumor markers test, the carcinoembryonic antigen (CEA, reference value $\leq 5.0 \mathrm{ng} / \mathrm{ml}$ ) and carbohydrate antigen 19-9 (CA19-9, reference values $\leq 37 \mathrm{U} / \mathrm{ml}$ ) were $0.58 \mathrm{ng} / \mathrm{ml}$ and $1,690 \mathrm{U} / \mathrm{ml}$, respectively.

The patient underwent an abdomen computerized tomography (CT) scan initially, and $2-{ }^{18}$ F-fluoro-2-deoxy-d-glucose (FDG) positron emission tomography (PET)-CT were requested to investigate the pancreatic abnormality. These studies demonstrated that the abdomen CT scan showed a large cystic mass with internal septa at the tail of the pancreas, and the FDG PET-CT image showed no abnormal FDG tracer uptake at the pancreatic cystic mass (Figs. 1, 2). The patient was suspected to have a pancreatic malignancy.

She underwent a laparotomy of the distal pancreatectomy and a splenectomy, with the intention of both diagnostic and therapeutic purposes. Operative findings revealed that a lesion with a diameter of $6.5 \mathrm{~cm}$ was located at the pancreatic tail, and its boundary was clear with adhesion to the spleen. In the fluid analysis of the

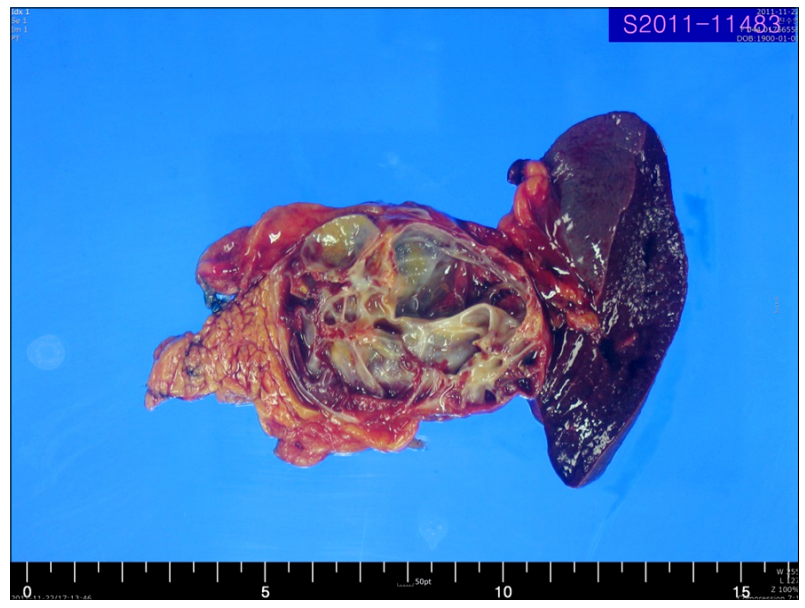

Fig. 3. A photograph of the gross specimen shows a 6.5 $\mathrm{cm}$-sized lymphoepithelial cyst of the pancreas tail. The cyst is well circumscribed and multilocular.

pancreas cystic mass, the CEA and CA19-9 were 618 $\mathrm{ng} / \mathrm{ml}$ and $3.9 \mathrm{U} / \mathrm{ml}$, respectively. The resected pancreas specimen showed a $6.5 \mathrm{~cm}$-sized cyst of the pancreas tail. The cyst was well circumscribed and multilocular (Fig. 3).

During the postoperative recovery period, the follow-up CA19-9 level was down to $5.8 \mathrm{U} / \mathrm{ml}$. The final pathology report of the resected pancreas specimen noted that the cyst was multilocular, and the cyst lining showed stratified squamous epithelium covering lymphoid tissue containing lymphoid follicles, which was consistent with a lymphoepithelial cyst (Figs. 4, 5). The patient recovered uneventfully from surgery and has been doing well for the past three months.

\section{DISCUSSION}

Cystic lesions of the pancreas can be divided into true cysts, pseudocysts, and cystic neoplasms. Pseudocysts are the most common cystic lesions of the pancreas and usu- 


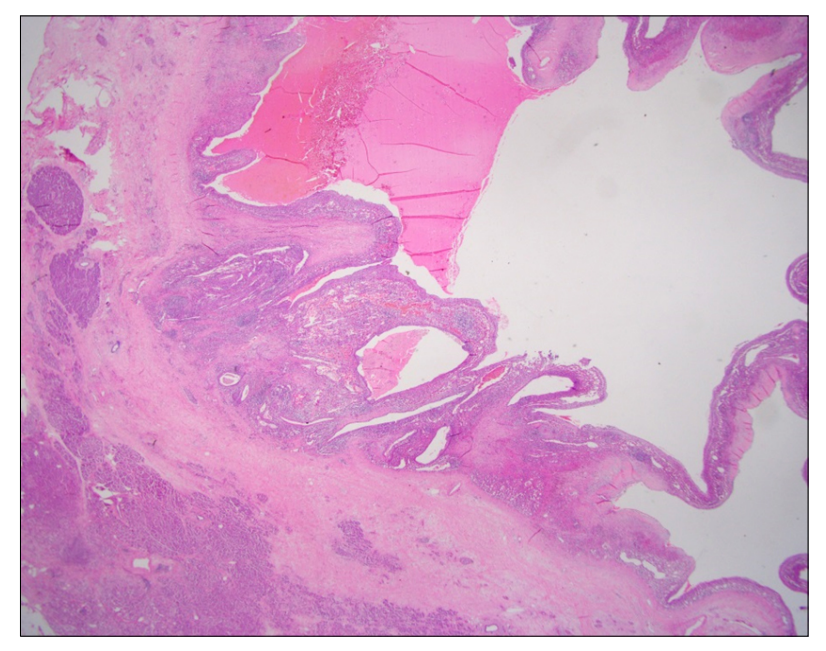

Fig. 4. A low-power view filed of the lymphoepithelial cyst. The cyst is multilocular, and the normal pancreatic parenchyma is seen in the lower left corner (H\&E, $\times 40)$.

ally occur as a complication of pancreatitis. True cysts, on the other hand, are most often neoplastic. Recently, cystic pancreatic lesions have been well recognized and classified because of the increased use and higher fidelity of cross-sectional imaging studies. ${ }^{4}$ However, in spite of the available technology, there is difficulty in differentiating benign cysts from those with malignant potential, with non-invasive imaging. ${ }^{5}$

Lymphoepithelial cysts of the pancreas are a rare non-neoplastic true cystic lesion, and they are defined as being a pancreatic cyst lined by mature squamous epithelium and surrounded by lymphoid tissue. The cyst arises typically in middle-aged men, and is usually either asymptomatic or causes nonspecific abdominal symptoms. There is no specific serologic marker for this entity.

The pathogenesis of lymphoepithelial cysts is uncertain. Osiro et al. ${ }^{3}$ reviewed the literature and identified the three most common theories, which are as follows: 1. squamous metaplasia in an obstructed duct, with subsequent cyst formation, 2. originating from the ectopic pancreas in a peri-pancreatic lymph node, and 3. lymphoepithelial cysts are due to the fusion of misplaced branchial cleft cysts with the pancreas during embryogenesis.

Some investigators suggest that the clinical and radiological findings are sufficiently characteristic of lymphoepithelial cysts to establish a preoperative diagnosis, and that conservative treatment can be selected for most asymptomatic lymphoepithelial cysts. ${ }^{6,7}$ Unfortunately, it

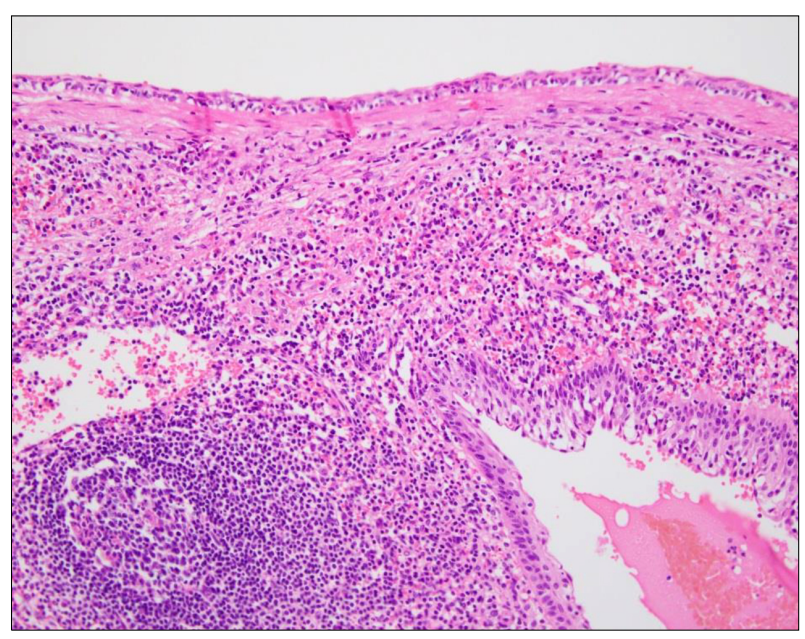

Fig. 5. A high-power view filed of the cyst-lining shows stratified squamous epithelium covering lymphoid tissue containing a lymphoid follicle $(\mathrm{H} \& \mathrm{E}, \times 200)$.

is actually not possible to differentiate these cysts from other types of pancreatic cystic neoplasms. Most are diagnosed, finally, after surgical resection. ${ }^{8}$ In lymphoepithelial cysts, almost one-half (44\%) of the cysts are unilocular, and more than one-half $(56 \%)$ of the cysts are located within the pancreas. Thus, the features pose a diagnostic dilemma in the preoperative workup of patients with pancreatic cysts, because they can mimic more common neoplastic mucinous cysts. ${ }^{9}$

In our case, the patient had a palpable abdominal mass and an elevated CA19-9 level. The abdominal CT finding showed a large cystic mass with internal septa in the tail of the pancreas, and the FDG PET-CT image shows no abnormal FDG tracer uptake at the pancreatic cystic mass. We could not rule out cystic neoplasm, so we performed distal pancreatectomy. During the operation, we checked for serologic markers of cystic content fluid, showing an elevated CEA level.

Postoperatively, the patient recovered uneventfully. The final pathology report of the resected pancreas specimen noted that the cyst was multilocular, and that the cyst lining showed stratified squamous epithelium covering lymphoid tissue containing lymphoid follicles, which was consistent with lymphoepithelial cyst.

In conclusion, differential diagnoses of cystic pancreatic lesions are important. Lymphoepithelial cysts, although very rare, may be included in the differential diagnosis of cystic pancreatic tumors. 


\section{ACKNOWLEDGEMENTS}

This work was supported by a research grant from Chungbuk National University, in 2012.

\section{REFERENCES}

1. Brugge WR, Lauwers GY, Sahani D, Fernandez-del Castillo C, Warshaw AL. Cystic neoplasms of the pancreas. N Engl J Med 2004;351:1218-1226.

2. Lüchtrath H, Schriefers KH. A pancreatic cyst with features of a so-called branchiogenic cyst. Pathologe 1985;6:217-219.

3. Osiro S, Rodriguez JR, Tiwari KJ, Rodriguez II, Mathenge N, Tubbs RS, et al. Is preoperative diagnosis possible? A clinical and radiological review of lymphoepithelial cysts of the pancreas. JOP 2013;14:15-20

4. Basturk O, Coban I, Adsay NV. Pancreatic cysts: pathologic classification, differential diagnosis, and clinical implications.
Arch Pathol Lab Med 2009;133:423-438.

5. Visser BC, Yeh BM, Qayyum A, Way LW, McCulloch CE, Coakley FV. Characterization of cystic pancreatic masses: relative accuracy of CT and MRI. AJR Am J Roentgenol 2007;189: 648-656.

6. Terakawa H, Makino I, Nakagawara H, Miyashita T, Tajima H, Kitagawa $\mathrm{H}$, et al. Clinical and radiological feature of lymphoepithelial cyst of the pancreas. World J Gastroenterol 2014;20: 17247-17253.

7. Kim WH, Lee JY, Park HS, Won HJ, Kim YH, Choi JY, et al. Lymphoepithelial cyst of the pancreas: comparison of CT findings with other pancreatic cystic lesions. Abdom Imaging 2013;38:324-330.

8. Adsay NV, Hasteh F, Cheng JD, Bejarano PA, Lauwers GY, Batts KP, et al. Lymphoepithelial cysts of the pancreas: a report of 12 cases and a review of the literature. Mod Pathol 2002;15: 492-501.

9. Raval JS, Zeh HJ, Moser AJ, Lee KK, Sanders MK, Navina S, et al. Pancreatic lymphoepithelial cysts express CEA and can contain mucous cells: potential pitfalls in the preoperative diagnosis. Mod Pathol 2010;23:1467-1476. 